\title{
Cervical collars in rheumatoid atlanto-axial subluxation: a radiographic comparison
}

\author{
BO ALTHOFF AND IAN F. GOLDIE
}

From the Department of Orthopaedic Surgery II, University of Göteborg, Göteborg, Sweden

SUMMARY Atlanto-axial subluxation occurs with a frequency varying from $6 \%$ to $45 \%$ in rheumatoid arthritis. Most patients are treated conservatively with a cervical collar. The effectiveness of different cervical collars in inhibiting anterior atlanto-axial subluxation was tested in 11 patients with classical rheumatoid arthritis. None of the collars had any major influence in inhibiting anterior subluxation of the atlas in maximal flexion. Furthermore, the harder collars with a stable cervical stand forced the atlas to subluxate anteriorly in some of the patients.

In rheumatoid arthritis the cervical spine becomes involved in more than a quarter of patients with seropositive disease. ${ }^{1}$ Clinical symptoms need not always accompany the radiographic appearance. ${ }^{2} 3$ The condition should, however, be observed, as fatal incidents like tetraplegia and even death may occur. $^{34}$ (Brattström, personal communication). Changes may develop in all cervical segments, but those most seriously considered are found in the atlanto-axial joints. An important stabiliser is the transverse ligament, which on its passage behind the odontoid process keeps this in close and firm contact with the anterior arch of the axis. The stability this ligament affords becomes jeopardised when erosions and destructions develop by the invasion of granulation tissue. The atlanto-axial joints may gradually dislocate. The distance between the odontoid process and anterior arch of the atlas may increase and eventually exceed the normal $2-3 \mathrm{~mm}$. This type of subluxation occurs with a frequency varying from $6 \%$ to $45 \%$, with a mean value of $20 \%{ }^{5}$

In order to diminish symptoms like headache and cervical pain and also to prevent a further dislocation which may be catastrophic, treatment aims at stabilising the spine either conservatively or surgically. Surgical methods have been described by Althoff and Goldie. ${ }^{6}$

Conservative methods include Minerva plaster and collars of different designs. The stabilising effect of

Accepted for publication 2 November 1979

Correspondence to Professor I. F. Goldie, Department of Orthopaedic Surgery II, Sahlgren Hospital, S-413 45 Göteborg, Sweden. most collars is not such that motion of the upper cervical spine becomes inhibited. This has been observed in normal individuals and described by Johnson et al. ${ }^{7}$ So far we have not seen any investigation on the stabilising effect of collars on individuals with spinal abnormalities, in particular the rheumatoid atlanto-axial subluxation. Consequently we present here our observations on the effectiveness of 4 different collars in 11 patients with rheumatoid atlanto-axial subluxation.

\section{Material and methods}

Eleven patients with classical rheumatoid arthritis and atlanto-axial subluxation were selected for this study. Four commonly used cervical collars were tested on each patient. Thus each patient served as his own control. The collars were: (1) Soft cervical collar (Fig. 1), (2) Philadelphia collar (Fig. 2), (3) SOMI brace (Fig. 3), and (4) 4-poster collar (Fig. 4). Lateral radiographs in flexion and extension were taken on the unrestricted cervical spine and after application of each of the 4 collars. The positions in maximal flexion and extension were estimated between the atlas and the axis, and the atlas and $\mathrm{C} 4$. One line was drawn along the superior margin of the arches of the atlas; one was drawn through the tips of the inferior lips of the body of the axis; and one likewise in relation to the body of $\mathrm{C} 4$. The 3 lines were extended until they intersected, and the angles were measured $^{8}$ (Fig. 5). The difference in angles between flexion and extension was recorded as the range of motion. Motion-angulation-developing 


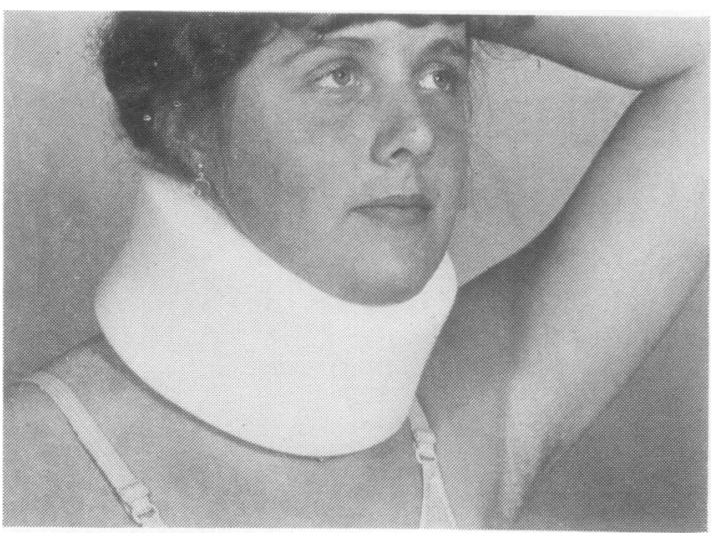

Fig. 1 Soft cervical collar.



Fig. 2 Philadelphia collar.

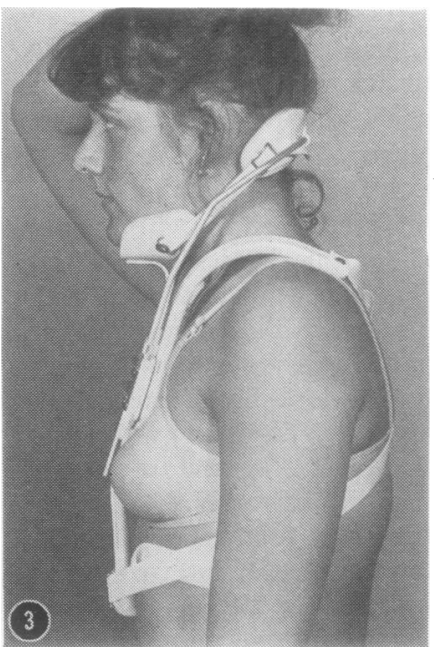

Fig. 3 SOMI brace. in the different collars between the atlas and the axis and the atlas and $\mathrm{C} 4$ was calculated and expressed as per cent of the motion of the unrestricted cervical spine.

In addition the distance between the posterior facet of the anterior arch of the atlas and the anterior surface of the odontoid process was recorded (Table 1).

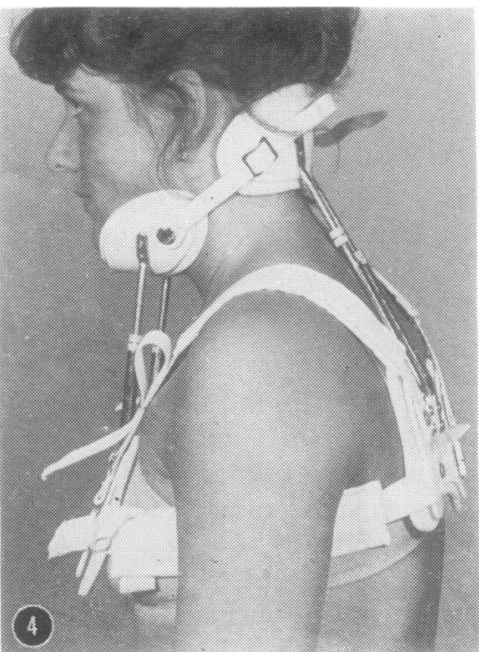

Fig. 4 Four-poster collar.

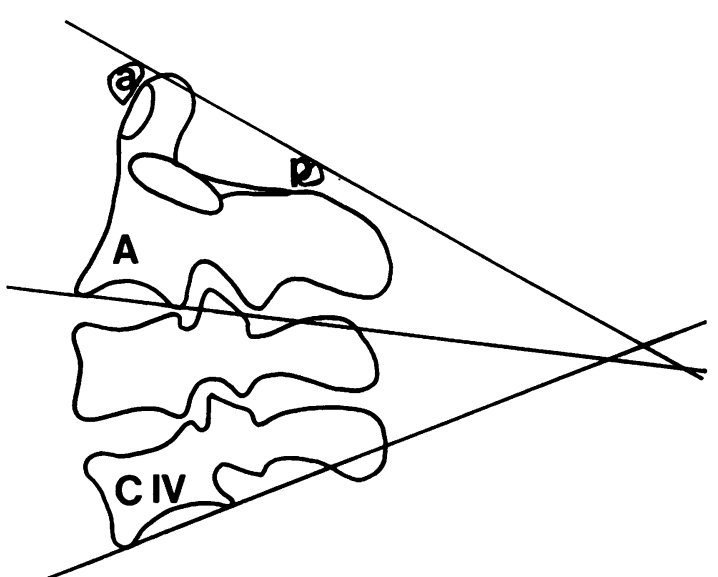

Fig. 5 Measurement of angles between the atlas and axis; between the atlas and C4 (according to Penning ${ }^{8}$ ). $\mathrm{A}=$ Axis. $\mathrm{a}=$ Anterior arch of atlas. $\mathrm{p}=$ Posterior arch of atlas. 
Table 1 Degree ( $\mathrm{mm}$ between atlas and odontoid process) of atlanto-axial subluxation in flexion and extension in 11 patients with rheumatoid arthritis after application of 4 different cervical collars

\begin{tabular}{|c|c|c|c|c|c|c|c|c|c|c|}
\hline \multirow[t]{2}{*}{ Patient } & \multicolumn{2}{|c|}{ Without support } & \multicolumn{2}{|c|}{ Soft collar } & \multicolumn{2}{|c|}{ Philadelphia collar } & \multicolumn{2}{|c|}{ SOMI brace } & \multicolumn{2}{|c|}{ Four-poster collar } \\
\hline & Flexion & Extension & Flexion & Extension & Flexion & Extension & Flexion & Extension & Flexion & Extension \\
\hline 1 & 9 & 4 & 9 & 3 & 8 & 4 & 9 & 8 & 9 & 7 \\
\hline 2 & 7 & 1 & 8 & 1 & 6 & 2 & 4 & 3 & 6 & 3 \\
\hline 3 & 11 & 2 & 11 & 2 & 11 & 2 & 11 & 2 & 11 & 2 \\
\hline 4 & 14 & 1 & 13 & 1 & 13 & 2 & 13 & 1 & 11 & 1 \\
\hline 5 & 21 & 20 & 21 & 20 & 18 & $1 \overline{8}$ & 17 & 17 & 19 & 17 \\
\hline 6 & 6 & 1 & 6 & 1 & 5 & 1 & 4 & 1 & 1 & 1 \\
\hline 7 & 12 & 2 & 11 & 2 & 9 & 2 & 10 & 8 & 9 & 9 \\
\hline 8 & 15 & 8 & 15 & 6 & 15 & 6 & 14 & 14 & 15 & 14 \\
\hline 9 & 16 & 13 & 15 & 15 & 16 & 14 & 17 & 17 & 15 & 15 \\
\hline 10 & 15 & 2 & 14 & 2 & 10 & 8 & 9 & 8 & 9 & 8 \\
\hline 11 & 9 & 8 & 9 & 8 & 9 & 9 & 7 & 6 & 8 & 6 \\
\hline
\end{tabular}

\section{Results}

UNRESTRICTED CERVICAL SPINE

The range of motion (angulation) in flexionextension of the 11 patients had a mean value of $20^{\circ}$ between the atlas and the axis and $28^{\circ}$ between the atlas and $\mathrm{C} 4$. The atlas was subluxated anteriorly in all 11 patients in flexion and reduced in extension in 6 patients. In 2 patients the subluxation remained in extension but was slightly decreased in comparison to the flexed position. In 3 the subluxation remained almost unchanged in extension.

SOFT COLLAR

With the soft collar a mean of $81 \%$ of the motion (angulation) remained between the atlas and the axis. The corresponding figure for motion between the atlas and $\mathrm{C} 4$ was $77 \%$. The atlanto-axial subluxation was almost unchanged in flexion as well as extension compared to the unrestricted cervical spine (Table 1).

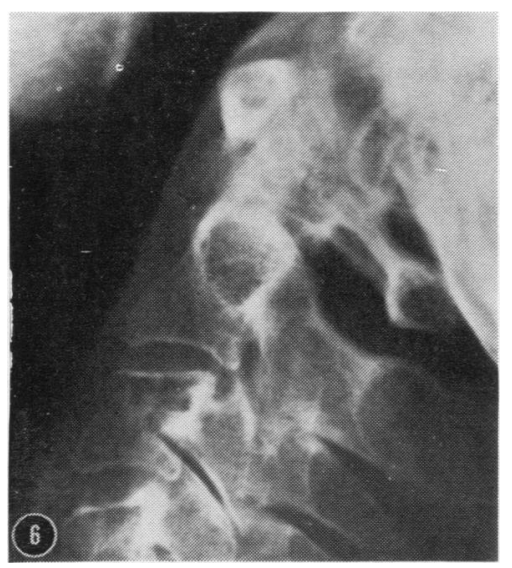

Fig. 6 Extension of unrestricted rheumatoid cervical spine. Good apposition of anterior arch of atlas to the odontoid process.

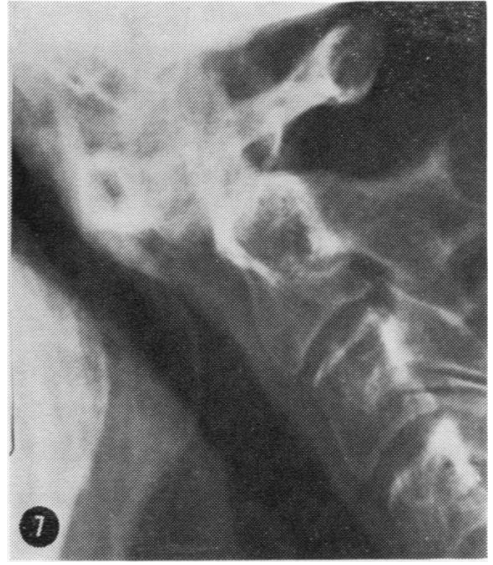

Fig. 7 Flexion of spine in Fig. 6. The movement is unrestricted. Atlanto-axial subluxation with $14 \mathrm{~mm}$ gap on original radiograph between anterior arch of atlas and odontoid process.

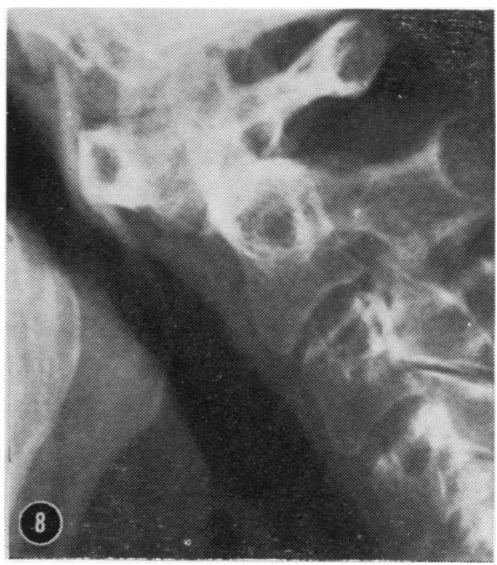

Fig. 8 Same as Fig. 7 but the cervical spine has now been stabilised with a soft collar. Atlanto-odontoid gap $=13 \mathrm{~mm}$. 
PHILADELPHIA COLLAR

With the Philadelphia collar a mean of $62 \%$ of the motion (angulation) remained between the atlas and the axis. The corresponding figure for the motion between the atlas and $\mathrm{C} 4$ was $51 \%$. The atlanto-axial subluxation was reduced a few millimetres in flexion but almost unchanged in extension when compared to the unrestricted cervical spine (Table 1).

\section{SOMI BRACE}

With the SOMI brace a mean of $62 \%$ of the motion (angulation) remained between the atlas and the axis. The corresponding figure for motion between

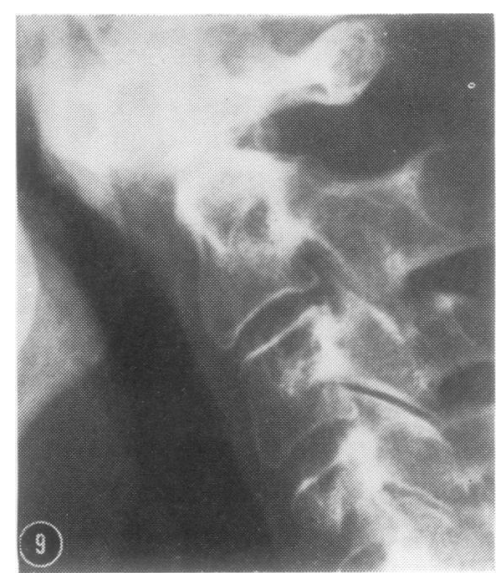

Fig. 9 Same as Fig. 7 but the cervical spine has now been stablised with a Philadelphia collar. Atlantoodontoid gap $=13 \mathrm{~mm}$ (on original radiograph).

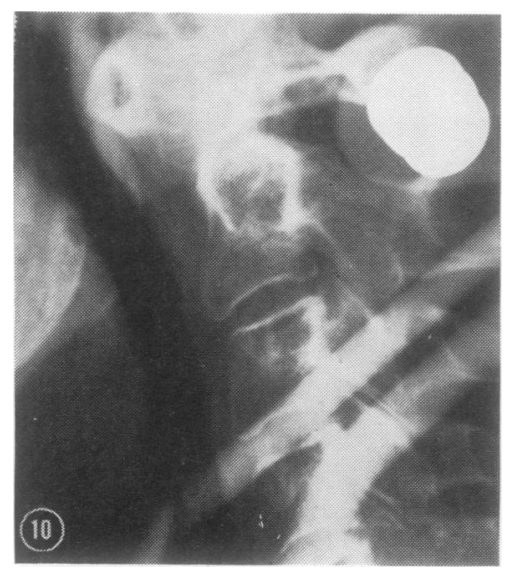

Fig. 10 Same as Fig. 7 but the cervical spine has now been stabilised with a SOMI brace. Atlanto-odontoid gap $=13 \mathrm{~mm}$ (on original radiograph).

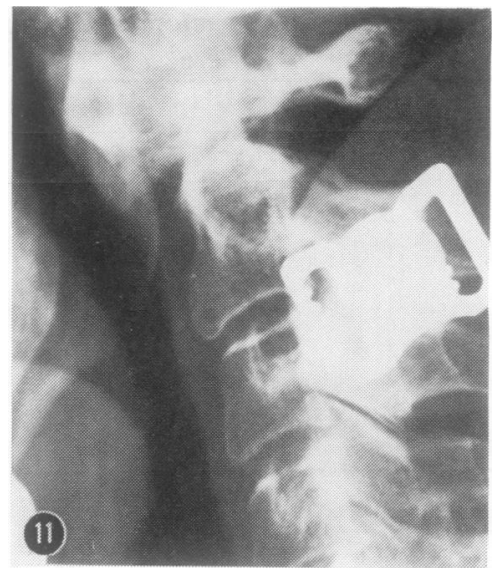

Fig. 11 Same as Fig. 7 but the cervical spine has now been stabilised with a 4-poster collar. Atlantoodontoid gap $=11 \mathrm{~mm}$ (on original radiograph).

the atlas and $\mathrm{C} 4$ was $56 \%$. The atlanto-axial subluxation was somewhat diminished in flexion but somewhat increased in extension compared to the unrestricted cervical spine (Table 1).

FOUR-POSTER COLLAR

With the 4-poster collar a mean of $54 \%$ of the motion (angulation) remained between the atlas and the axis. The corresponding figure for the motion between the atlas and $\mathrm{C} 4$ was $47 \%$. The atlanto-axial subluxation was reduced a few millimetres in flexion by this collar but increased in maximal extension compared to the unrestricted cervical spine (Table 1).

\section{Discussion}

In this investigation the estimated range of motion (angulation; $\sim 20^{\circ}$ ) between the atlas and the axis in the rheumatoid patients was somewhat increased when compared to the observations of White ${ }^{9}$ in normal persons $\left(\sim 10^{\circ}\right)$. On the other hand the motion between the atlas and $\mathrm{C} 4$ in these rheumatoid cervical spines $\left(28^{\circ}\right.$, thus leaving only $8^{\circ}$ for the axis-C4 region) was diminished when compared to the normal cervical spines $\left(43^{\circ}\right.$; leaving $30^{\circ}$ for the axis-C4 region) as investigated by Johnson et $a .^{7}$ This indicates that the rheumatoid cervical spines in this investigation were stiffer in the articulations between the axis and $\mathrm{C4}$. The rheumatoid arthritis can manifest itself in the cervical spine below the axis both as a subluxation and/or as an ankylosis between the vertebrae, which causes the decreased mobility.

The effectiveness of the different collars as 
stabilisers on cervical motion was not satisfactory in this investigation, as 47 to $81 \%$ of unrestricted motion was permitted. In view of this it is not surprising that no collar afforded any significant stability to the atlanto-axial subluxation. Another observation was that the firmer collars with a stable occipital seat forced the atlas to subluxation anteriorly when the head was extended and pressed against the posterior support. However, it cannot be denied that a collar has a great psychological value and may offer some relief of pain. Moreover, the comfort a collar affords by its warming effect may have a protective purpose in giving the patient a feeling of stability, which is of utmost importance in everyday life with its varying activities like travelling in jolting vehicles, moving in pushy crowds, and being helped in and out of beds, chairs, and suchlike.

The study was supported by the Göteborg Medical Society and the Svenska Livförsäkringsbolags fund for medical research.

\section{References}

1 Boyle A C. The rheumatoid neck. Proc R Soc Med 1971; 64: 1161-8.

2 Bland J H, Davis P H, Conlon M G, van Buskirk F W, Duart C G. Rheumatoid arthritis of the cervical spine. Arch Intern Med 1963; 112: 892-8.

3 Hopkins J S, Lower cervical rheumatoid subluxation with tetraplegia. J Bone Joint Surg 1967; 49B: 46-51.

4 Mikulowski P, Wollheim F A, Rotmil P, Olsen I. Sudden death in rheumatoid arthritis with atlanto-axial dislocation. Acta Med Scand 1975; 198: 445-51.

5 Dirheimer Y. The Craniovertebral Region in Chronic Inflammatory Rheumatic Diseases. Berlin: Springer, 1977.

6 Althoff B, Goldie I F. An alternate method for posterior fixation in anterior and inferior atlanto-axial dislocation. Arch Orthop Trauma Surg 1979; 93: 243-8.

7 Johnson R, Hart D, Simmons E, Ramsby G. Cervical orthoses: a study comparing their effectiveness in restricting cervical motion in normal subjects. $J$ Bone Joint Surg 1977; 59A: 332-9.

8 Penning L. Functional Pathology of the Cervical Spine. Amsterdam: Excerpta Medica, 1968: 196.

9 White A A III, Johnson R, Panjabi M, Southwick W. Biomechanical analysis of clinical stability in the cervical spine. Clin Orthop 1975; 109: 85-96. 